\title{
Muscle nuclear size in neuromuscular disease
}

\author{
D. VASSIlopoulos, E. M. LUMB, AND A. E. H. EMERY \\ From the Department of Human Genetics, University of Edinburgh, \\ Western General Hospital, Edinburgh
}

SYNOPSIS Nuclear size has been estimated in muscle biopsy specimens from seven healthy individuals, eight patients with infantile spinal muscular atrophy (types I and II), and eight patients with Duchenne muscular dystrophy. The results indicate a great increase in nuclear size in Duchenne muscular dystrophy but not in spinal muscular atrophy when compared with controls. The reasons for this finding are discussed in relation to the pathogenesis of these two groups of diseases.

Neuromuscular diseases are generally divided into two categories: the neuropathies and the myopathies. Although much research has been devoted to these diseases, their exact pathogenesis remains obscure. The histological and histochemical alteration of the muscle fibres in these diseases has been well documented but little attention has been paid to the muscle cell nucleus. Although at the moment it is impossible to detect the primary single gene defect of these hereditary diseases, an examination of the nucleus may indicate the extent of its participation in the pathological process.

The flexible nature of the muscle nucleus is indicated during normal post-natal muscle development when there is an increase in size and number of muscle fibres (Cheek, 1968). A similar increase in size and/or number of nuclei would also be expected in order to keep the nuclear-cytoplasmic ratio within certain limits.

Such an increase in nuclear size accompanies the consequent cellular hypertrophy after partial ablation of the liver (Stowell, 1948; Hammarsten, 1951; Harkness, 1952; Wilson et al., 1953) or kidney (Sulkin, 1949; Schmiedt, 1951; Fajers 1957) in experimental animals. Enlargement of cell nuclei has also been observed in the cirrhotic liver (Guimarães, 1971) as well as in the thyroid gland (Alfert et al., 1955) and hypothalamus (Bandaranyake, 1974) in certain experimental conditions. We decided to determine muscle nuclear size in infantile spinal muscular atrophy

(Accepted 29 August 1975.) (types I and II) and in Duchenne muscular dystrophy in the hope that the results might throw more light on the pathogenesis of these diseases.

\section{METHODS}

The material used in this study consisted of seven control subjects (mean age 2.4 years), eight patients with type I (Werdnig-Hoffmann) and type II (Fried and Emery, 1971) spinal muscular atrophy (mean age 2.8 years, and mean duration of illness 0.8 years) and eight patients with Duchenne type muscular dystrophy (mean age 4.7 years, mean duration of illness 3.0 years). The age and sex of the individuals are shown in the Table.

The diagnosis in all cases was based on clinical examination and confirmed by biochemical (serum creatine kinase levels) and electrophysiological (electromyography, nerve conduction velocity) studies as well as by muscle histology. In almost all cases the vastus lateralis was the muscle biopsied. Haematoxylin and eosin stained frozen sections were used. The origin of each slide was masked and four randomly chosen fields were photographed. The negatives were enlarged to give a final magnification of $\times 1000$ and the areas of 100 nuclei closely opposed to the surface of the transversely sectioned muscle fibre were measured by planimetry. The nuclei were selected for measurement in this way in order to eliminate fibroblast, pericyte, endothelial cell, and satellite cell nuclei. It should be noted that in spinal muscular atrophy nuclei of both large and atrophic fibres were measured. In the present study only nuclear areas in the transverse plane of the muscle fibres were estimated (Figure), since any estimation of nuclear volume would require certain assumptions 


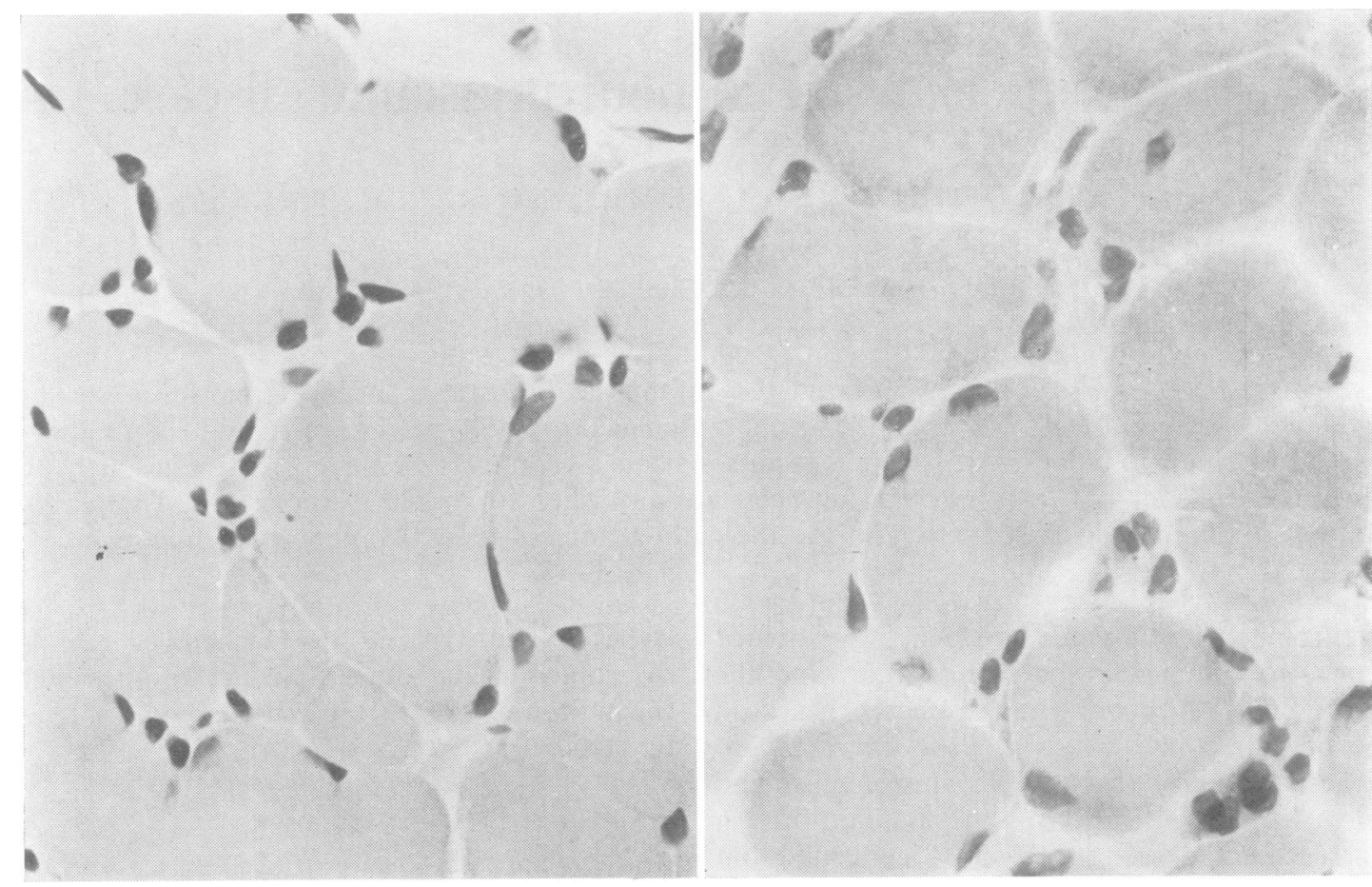

FIGURE Transverse section of muscle in spinal muscular atrophy (left) and Duchenne muscular dystrophy (right). Cryostat sections stained with haematoxylin and eosin, $\times 500$.

TABLE

NUCLEAR AREA IN MUSCLE BIOPSY SPECIMENS FROM CONTROLS AND PATIENTS WITH SPINAL MUSCULAR ATROPHY AND DUCHENNE MUSCULAR DYSTROPHY (RESULTS EXPRESSED AS MEAN \pm SD)

\begin{tabular}{lclll}
\hline Group & Identification & Sex & $\begin{array}{c}\text { Age } \\
(y r)\end{array}$ & $\begin{array}{c}\text { Nuclear area } \\
\left(\mu m^{2}\right)\end{array}$ \\
\hline & B84 & M & 1 & $22.25 \pm 7.03$ \\
Controls & 138348 & F & 2.5 & $29.57 \pm 9.61$ \\
& 144063 & F & 1.5 & $29.39 \pm 11.5$ \\
& B23 & M & 6 & $22.14 \pm 8.96$ \\
& B52 & M & 2.5 & $14.8 \pm 5.11$ \\
& B53 & M & 1.5 & $20.74 \pm 7.08$ \\
Spinal muscular & B51 & M & 2 & $22.2 \pm 6.76$ \\
atrophy & $\mathbf{8 2 2 3}$ & M & 6 & $14.21 \pm 3.87$ \\
& J.Q. & M & 6 & $31.49 \pm 9.26$ \\
& B48 & F & 1 & $22.36 \pm 7.80$ \\
& 131590 & M & 3 & $21.54 \pm 7.55$ \\
& B62 & F & 0.5 & $22.22 \pm 5.99$ \\
& B32 & M & 0.5 & $30.94 \pm 9.96$ \\
& B10 & F & 4 & $15.65 \pm 4.37$ \\
& B72 & M & 1.5 & $20.86 \pm 8.19$ \\
Duchenne muscular & B70 & M & 5.5 & $28.94 \pm 10.21$ \\
dystrophy & B65 & M & 5 & $33.12 \pm 14.04$ \\
& B73 & M & 3.5 & $31.02 \pm 8.57$ \\
& B28 & M & 6 & $27.87 \pm 8.16$ \\
& B63 & M & 4.5 & $22.6 \pm 7.87$ \\
& B36 & M & 2 & $25.41 \pm 7.16$ \\
& B34 & M & 5.5 & $34.89 \pm 13.85$ \\
& B47 & M & 6 & $34.02 \pm 12.84$ \\
\hline & & & &
\end{tabular}

to be made upon the irregular shape of the muscle nucleus (Franke and Schinko, 1969) and since the freezing technique would clearly affect nuclear size, all material was treated in an identical manner. The mean nuclear area and the standard deviation were calculated and the origin of each slide then unmasked so that the material could then be identified.

\section{RESULTS}

From the results in the Table, it will be seen that there is some overlap of individual values between the three groups but the overall mean of the mean areas of nuclei in patients with Duchenne muscular dystrophy $\left(29.73 \pm 4.33 \mu \mathrm{m}^{2}\right)$ is significantly greater $(\mathrm{P}<0.02)$ compared with controls $\left(23.01 \pm 5.13 \mu \mathrm{m}^{2}\right)$ and patients with spinal muscular atrophy $\left(22.41 \pm 6.22 \mu \mathrm{m}^{2}\right)$. There was no significant difference between the values in patients with spinal muscular atrophy and control subjects.

The observed differences could not be correlated with the patient's age or sex. In addition, 
in the dystrophic group there was no correlation between the nuclear area and various clinical parameters-for example, duration of illness, serum creatine kinase levels.

\section{DISCUSSION}

Altered nuclear size has been observed in a number of human diseases. Guimarães (1971) found significantly increased nuclear volumes in the cirrhotic liver but, since this hypertrophy was not correlated with the functional activity of the hepatocytes, the cause of this change remained unclear. Heiberg (1957) described quantitative nuclear changes in cancer cells which he regarded as fundamental not only as a diagnostic aid but also indicative of the prognosis of various malignant tumours. An alteration of nuclear size has also been detected in a number of experimental conditions. Bandaranyake (1974), observing alterations in the size of the hypothalamic neurone nuclei under certain experimental conditions (dehydration, water loading, lactation, etc.), related this to the functional state of the organ. In a similar way, Alfert and his colleagues (1955) found enlarged thyroid epithelium nuclei and, in addition, they concluded that this increase was due to increased amounts of non-histone proteins since the DNA and histone content remained the same.

With reference to muscle cell nuclei some workers have attempted to correlate nuclear shape with the degree of muscle contraction (Franke and Schinko, 1969), altered ionic environment (Davies and Spencer, 1962), and cellular hypertrophy (Doljanski, 1960; Goss, 1964). In the present study, the reasons for the increase in the area of muscle nuclei in Duchenne muscular dystrophy are not immediately apparent. Since the change in nuclear size seems unlikely to be a direct result of the primary gene defect, it is probably a reflection of modified nuclear-cytoplasmic alterations.

In addition to DNA, the nucleus contains appreciable quantities of histones and nonhistone proteins. Current concepts of gene expression consider that histones repress genes, whereas non-histone proteins selectively derepress genes. An increase in the amount of non-histone proteins in response to increased functional demands of the cytoplasm may explain the increase in nuclear size. We are carrying out histochemical studies on the muscle nucleus to determine if the observed increased size of muscle nuclei in Duchenne muscular dystrophy can be explained in this way.

In conclusion, the observed increase in nuclear size in Duchenne muscular dystrophy compared with spinal muscular atrophy patients indicates a fundamental difference between the two disorders. The precise nature of this increase is at present unclear, although future histochemical studies on the nucleus may provide further information on the pathogenic mechanisms operating in Duchenne dystrophic muscle.

This work was supported by the Muscular Dystrophy Group of Great Britain. Dr D. Vassilopoulos is a scholar of the State Scholarship Foundation of Greece.

\section{REFERENCES}

Alfert, M., Bern, H. A., and Kahn, R. H. (1955). Hormonal influence on the nuclear synthesis. Acta Anatomica, 23, 185-205.

Bandaranayake, R. C. (1974). Karyometric study of hypothalamic neurosecretory neurones under different conditions. Acta Anatomica, 90, 431-461.

Cheek, D. B. (1968). Muscle cell growth in normal children. In Human Growth, pp. 337-351. Lee and Febiger: Philadelphia.

Davies, H. G., and Spencer, M. (1962). The variation in the structure of erythrocyte nuclei with fixation. Journal of Cell Biology, 14, 445-458.

Doljanski, F. (1960). The growth of the liver with special reference to mammals. International Review of Cytology, 10, 217-241.

Fajers, C. M. (1957). On compensatory renal hypertrophy after unilateral nephrectomy. 1. Karyometric study. Acta Pathologica et Microbiologica Scandinavica, 41, 25-33.

Franke, W. W., and Schinko, W. (1969). Nuclear shape in muscle cells. Journal of Cell Biology, 42, 326-331.

Fried, K., and Emery, A. E. H. (1971). Spinal muscular atrophy, type II. Clinical Genetics, 2, 203-209.

Goss, R. I. (1964). Adaptive Growth, p. 147. Academic Press: London.

Guimarães, R. C. (1971). The relationship between the nuclear volumes and the DNA contents of the hepatocyte nuclei, in the normal liver, in the hepatosplenic form of Mansoni schistosomiasis and in hepatic cirrhosis. Revista Brasiliera de Pesquisas Medicas e Biologicas, 4, 169-183.

Hammarsten, E. (1951). Turnover rates during formation of proteins and polynucleotides in regenerating tissues. In Ciba Foundation Conference on Isotopes in Biochemistry, pp. 203-212. Edited by G. E. W. Wolstenholme. Churchill: London.

Harkness, R. D. (1952). Changes in the liver of the rat after partial hepatectomy. Journal of Physiology, 117, 267-277.

Heiberg, K. A. (1957). Über die Erklärung einer Verschiedenheit der Krebszellen von anderen zellen. Nordisk Medicinhistorisk Arsbok, 8, 1-20.

Schmiedt, E. (1951). Zellkerngrösse und sogenannte kompen- 
satorische Hypertrophie der Mauseniere. Zeitschrift für mikroskopisch-anatomische Forschurg, 57, 249-275.

Stowell, R. E. (1948). Nucleic acid and cytologic changes in regenerating rat liver. Archives of Pathology, 46, 164-178. Sulkin, N. M. (1949). Cytologic studies of the remaining kidney following unilateral nephrectomy in the rat. Anatomical Record, 105, 95-112.

Wilson, M. E., Stowell, R. E., Yokoyama, O., and Tsuboi, K. K. (1953). Cytological changes in regenerating mouse liver. Cancer Research, 13, 86-92. 